\title{
Acesso a Medicamentos X Globalização: Análise Sobre o Papel do Direito
}

Carlos Maria Gambaro ${ }^{(*)}$

\section{RESUMO}

Neste artigo, buscar-se-á analisar o papel desempenhado pelo Direito, em face das convergências e tensões criadas nas interações entre a globalização e o acesso a medicamentos no cenário internacional, buscando verificar os pontos de coesão e incongruência entre os discursos então vigentes e a realidade, traçando um paralelo entre o desenvolvimento dos modelos econômicos e a garantia de acesso dos menos favorecidos a remédios.

\section{Palavras-chave}

Acesso a Medicamentos; Direito à Saúde; Globalização.

\begin{abstract}
This article will examine the role played by Law, given the similarities and tensions created in the interaction between globalization and access to medicines in the international arena. It will analyse the points of cohesion and incongruence between the speeches and the reality, showing the parallel between the development of economic models and the guarantee of drug access for the poorest population.
\end{abstract}

\section{Key words}

Drug Access; Globalization; Right to Health.

(*) Professor de Direito Internacional no Centro Universitário Nove de Julho - UNINOVE, Doutorando em Serviços de Saúde Pública na Faculdade de Saúde Pública da Universidade de São Paulo. E-mail: <carlosgambaro@gmail.com>. Recebido em 13.9.6 Aprovado em 5.5.7. 


\section{INTRODUÇÃO}

A partir do reconhecimento da saúde como direito inalienável do homem, o acesso (ou falta dele) a medicamentos passou a ser tema da mais alta relevância e, ao mesmo tempo, forte gerador de controvérsias, pois trouxe à tona diversas discussões e, dentre as mais importantes, o aparente paradoxo entre ampla oferta de remédios e os interesses econômico-comerciais dos laboratórios que desenvolvem e fabricam estes medicamentos.

Neste trabalho, inicialmente, analisar-se-á a emergência da ciência jurídica moderna, bem como o surgimento do Direito à Saúde e suas relações com os cenários político-econômicos mundiais, de forma a determinar suas características e princípios, bem como permitir diagnosticar quais as conseqüências atuais de sua base filosófico-estrutural.

Posteriormente, será feita uma breve análise do fenômeno da globalização, avaliando suas características e influências na ciência jurídica e reflexos no acesso a medicamentos.

Finalmente, serão abordadas as relações, interações e influências entre o Direito e o acesso a medicamentos, analisando-se o papel desempenhado pela ciência jurídica em prol (ou mesmo contra) o direito ao acesso de remédios, bem como a relação fática de ambos com o fenômeno da globalização, buscando diagnosticar a importância que o Direito tem atualmente para a consecução desta finalidade humanitária e, em caso de deficiências, quais alternativas, dentro ou fora do Direito, se apresentam para suplantar eventuais falhas, ou colmatar possíveis lacunas jurídicas.

\section{DO DIREITO À SAÚDE}

Com o triunfo da revolução burguesa sobre o modelo hierárquico de privilégios do Absolutismo, se consolida também uma nova forma de organização social e uma nova forma de pensar o Direito, respectivamente, o capitalismo e o Direito Natural.

O jusnaturalismo apregoa a existência de determinados direitos imanentes ao ser humano pelo simples fato de o indivíduo pertencer à raça humana e, dentre estes direitos naturais, vislumbra-se o surgimento da percepção de que a saúde é um direito a ser garantido ao homem.

Há que ficar claro, contudo, que a saúde neste estágio não possuía a característica de política pública, ou seja, não é um direito a ser defendido para uma coletividade, mas ao contrário, é tópica e, muitas vezes, filantrópica ou benemerente. Na verdade, o próprio modelo filosófico e organizacional da sociedade, baseado na idéia de que todos são iguais e que pelas próprias forças devem alçar-se da pobreza e das mazelas acarretadas por ela (incluindo-se aqui a doença) não permitia que um entendimento de saúde social 
prospere-se, pois se está minando o pilar filosófico de que a igualdade é característica ampla e irrestrita do homem, para se reconhecer a existência de indivíduos incapazes de sobreviver e se desenvolver por seus próprios esforços.

Uma vez consolidados os princípios e pensamentos burgueses, o discurso jurídico passa do jusnaturalismo para o positivismo, o qual, até certo ponto, rejeita os direitos naturais, filiando-se ao direito escrito, equiparando as noções de legítimo e justo à noção de legalidade.

O positivismo jurídico assenta-se no entendimento de que valores (como moral e justiça), pelo fato de não serem absolutos, de forma que deveriam ser discutidos e considerados no tempo e no espaço, são relativos e em virtude disso não podem embasar a ciência jurídica, sob pena de existir uma perene instabilidade e ausência de segurança, visto que, com a mudança de entendimento sobre um valor as decisões proferidas também, invariavelmente, deveriam acompanhar a alteração de noção ou juízo.

Em resposta à instabilidade, o positivismo adota como base a estrutura formal do Direito, sem valorações. O Direito passa a valorizar não o fundo, mas sim a forma, ou seja, se a decisão é tomada de acordo com os procedimentos preestabelecidos, ela é válida.

Do ponto de vista econômico, vive-se o auge do liberalismo, onde a grande preocupação capitalista é impor limites à atuação intervencionista do Estado Moderno, pois este representa o maior perigo aos interesses e atividades do capitalista liberal, mas sem o qual o modelo liberal não pode existir.

A adoção do positivismo é a saída encontrada para frear o ímpeto estatal, mediante a criação de princípios como:

a) legalidade - de modo que o Estado somente intervém na liberdade dos indivíduos (em prol do interesse geral), se percorrer os trâmites e processos previstos na própria lei para validade de uma norma;

b) publicidade - os atos do Estado devem ser claros, transparentes e dados a conhecer aos indivíduos, pois podem pôr em risco a garantia dos interesses individuais;

c) separação de poderes - os poderes devem ser tripartidos (Executivo, Legislativo e Judiciário) de forma a que um fiscalize e supervisione (e, portanto, restringindo) a atuação do outro.

Em um período histórico dominado pelo formalismo jurídico, sistema econômico orientado pela livre iniciativa e com uma estrutura social liberal, o Direito à saúde e, mais especificamente o direito ao acesso a medicamentos (essenciais ou não), não possue terreno fértil para se desenvolver. Neste momento histórico, ambos ainda ficam relegados a atividades tópicas e 
pontuais (como nos casos de epidemias) e em sua maioria são tratados como assuntos de filantropia ou benemerência.

Esta situação somente modifica-se na segunda metade do século $X X$, quando, em virtude da organização das classes trabalhadoras, estas passam a se opor às imposições e explorações do sistema capitalista-liberal, configurando-se como contraponto aos interesses do capital.

Surge o denominado Estado de Bem-Estar Social ou Welfare State, o qual seguindo o modelo keyneseano passa a intervir na economia com a finalidade de implementar políticas públicas (como p. ex. o pleno emprego), buscando coordenar as forças e tensões criadas pelo capitalismo sob sua modalidade liberal.

Por trás do Welfare State, reside a tentativa de administrar o crescente conflito entre o capital e a força de trabalho, sem, contudo, buscar sua superação. Trata-se de reconhecer a assimetria do poder do capital frente ao poder do trabalho e, conseqüentemente, as diferenças das diversas camadas populares, ou seja, em suma, reconhecer a falácia do ideal revolucionário burguês de que todos os seres humanos são iguais, visando amenizar tal desigualdade, mas não extingui-la, visto que mesmo o Estado welferista dependia da produção e do acúmulo de riquezas, ou seja, dependia do capitalismo, que, por sua vez, é uma ordem que tende a criar desigualdades.

Juntamente com este movimento político, o Direito se desenvolve, abandonando o liberalismo e adotando uma racionalidade social, voltando-se para a busca de "domesticação" do capital, reconhecendo a necessidade da coletivização do social e uma ordem jurídica mais protecionista, dos agora considerados indivíduos mais frágeis.

Esta nova forma de pensamento jurídico caracteriza-se pela:

a) aproximação entre a esfera pública e a esfera privada, ou publicização do privado e privatização do público, onde as partes do conflito (mais perceptível nas relações de trabalho) não mais são consideradas iguais, colocando-se o Estado como mediador das tensões existentes em benefício do ator social agora considerado hipossuficiente (trabalhador/consumidor);

b) politização do Direito - questões políticas ou ideológicas passam a ter caráter jurídico (reincorporação ao Direito de noções de valores), ocorrendo também o inverso, temas jurídicos passando a ser mais politizados, recebendo forte carga ideológica ( $p$. ex. noção de saúde como direito e princípio de igualdade);

c) reconfiguração dos ramos clássicos do Direito, diante da necessidade de maior interferência do Estado nas atividades particulares; 
d) aproximação do Direito com a economia, com a introdução de normalização técnica e altamente especializada para os setores financeiro e econômico; e

e) pelo surgimento da geração dos direitos sociais, em contraposição ao pensamento jurídico liberal.

O Direito social pressupôs uma forte e ativa participação estatal nos setores social e econômico, pois para a garantia de tais "novos" direitos, a simples ausência ou abstinência estatal (pressupostos e requisitos da garantia dos direitos liberais) não bastavam.

Neste cenário, surge a idéia da necessidade de proteção à saúde dos atores sociais, notadamente dos considerados hipossuficientes. Assim, emerge o Direito Sanitário como direito social, na medida em que o Estado, ao publicizar as relações privadas, busca criar uma rede de proteção social exigida pela classe trabalhadora. O Direito social procura agora resultados, visando uma racionalidade finalística das normas programáticas.

Como conseqüência da ascensão do Direito Sanitário e dos Direitos Sociais, desenvolve-se a percepção de que se faz necessário criar um sistema (ou política) para garantir o acesso a remédios aos hipossuficientes, visto que, ao lado da prevenção, os medicamentos têm papel fundamental na promoção da Saúde.

Observa-se, portanto, que a percepção da necessidade de garantir acesso a medicamentos aos hipossuficientes surge em decorrência do momento histórico em que o Direito (social) aponta para uma socialização progressiva dos direitos garantidos pelo Estado, passando o ente público a conter em seu cerne um pressuposto ético, um mínimo de moral, compromissado com uma justiça distributiva e não apenas comutativa. Combatese, portanto, a racionalidade jurídica e política, a qual era umbilicalmente ligada ao ideal liberal.

Contudo, o Estado de bem-estar funciona baseado nas premissas de que, se por um lado é necessário "domesticar" o capitalismo, visto que ele era criador de disparidades e dominação, pelo outro, o próprio Estado tem que se ocupar de maximizar a criação e renovação de riquezas, já que, sem dinheiro, não há como atingir suas finalidades de pleno emprego e desenvolvimento de programas voltados a equacionar e organizar os conflitos entre as camadas sociais.

Esta atuação estatal gera dívidas e déficits, o que mina o modelo do Welfare State. Fragilizado e diante do rápido avanço tecnológico e científico, o modelo de bem-estar abria brechas para uma nova forma de capitalismo, o neoliberalismo.

A partir dos anos 70, a economia capitalista atingiu tal grau de competitividade internacional que reduziu a eficácia das políticas econômicas key- 
nesianas cujo bom funcionamento se dava apenas, até então, em escala nacional. O neoliberalismo, em contrapartida, forçava a abertura das economias nacionais ao mercado internacional(1).

O Welfare State não comporta mais os anseios capitalistas que viam a necessidade de maior liberdade para suas transações, tanto internas como internacionais ${ }^{(2)}$. Tomaram então, os pensadores, apoiados pelos empresários, a bandeira do neoliberalismo de Hayek e Friedman (assim como tomam partido de qualquer outra doutrina que pregasse o afastamento do paternalismo estatal, prejudicial para eles na época).

A partir deste momento, todo o pensamento econômico, político e social sofre uma guinada, rumando para o abandono das práticas até então vigentes no século XX, assumindo as feições que moldam a atual globalização.

É um período fértil e próspero para as economias de praticamente todos os países desenvolvidos, isto é, após a $2^{\mathrm{a}}$ Guerra Mundial não ocorre nenhuma crise profunda, como o advento de uma $3^{\text {a }}$ Guerra Mundial, ou um crash como o de 1929. Ao contrário, ano após ano as economias centrais (Estados Unidos, Japão e Europa) crescem, de forma variável, é verdade, mas, sem experimentar fortes recessões. $O$ único conflito digno de nota no interregno 1970-2000 (afora o final da Guerra do Vietnã) é a denominada Guerra Fria, travada nas brumas pelas duas superpotências Estados Unidos e União Soviética (URSS).

Do lado político, cada potência procura exercer influência sobre sua "comunidade de protegidos", promovendo um maior inter-relacionamento entre os países formadores dos dois blocos. Por sua parte, a URSS "proclamava o seu papel de defensora da igualdade social, combatendo, para tanto, o imperialismo capitalista"(3).

O bloco antagônico, por sua vez, tem nos EUA o paradigma a ser seguido. Como campeão do capitalismo, ele faria tudo que estivesse ao seu alcance para fomentar a doutrina da abertura econômica entre os países, dentro de sua área de influência. Ou seja, cabe a ele a função primordial de apontar os benefícios de uma economia aberta, onde a livre circulação de bens e mercadorias, fora do controle estatal, constitue a pedra angular.

(1) CARMO, Paulo Sérgio do. O trabalho na economia global. 2. ed. São Paulo: Moderna, 1998. 72 p.

(2) Um fator determinante para triunfo do liberalismo, ou neoliberalismo, sobre o keyseanismo (reconhecidamente mais benéfico para a população em geral) foi o desenvolvimento dos transportes e das telecomunicações. Nesse momento, com o incremento na qualidade e segurança dos meios de transportes, ficou mais fácil a movimentação tanto de cargas como de passageiros, de modo que as possibilidades de expansão para além das fronteiras nacionais foram potencializadas. Do mesmo modo a comunicação também cresceu em quantidade e qualidade, permitindo a manutenção de relações com maior facilidade, o que contribuiu de forma definitiva para o aumento do volume de negócios entre particulares de diferentes Estados.

(3) Op. cit., p. 24. 
Pelo lado comercial, o bloco soviético mantém suas trocas internas determinadas com base nas planificações econômicas e nos verdadeiros auxílios comerciais enviados pela URSS, de forma crônica ou não, para os demais países. Quanto aos capitalistas, os EUA postulam pela ausência de barreiras ao comércio, constituindo-se ele mesmo, no maior trader do bloco. Incentivavam a produção e exportação (bem como a importação) de produtos para inibir o avanço do socialismo.

Outro elemento característico da Guerra Fria, a corrida armamentista, se por um lado traz terror e apreensão, por outro, é um fator determinante para o rápido desenvolvimento de diversos tipos de tecnologias (dentre elas comunicação, transportes e biotecnologia).

No campo do pensamento econômico e político, surge a idéia da liberdade de ação dos particulares (reunidos em grandes conglomerados empresariais) e a repulsa à intervenção estatal nas atividades da economia. Ao lado destas, o comércio internacional experimenta um incremento monumental, dando origem aos foros mundiais, onde os países centrais passam a se reunir para discutir economia e comércio.

O Direito, por sua vez, passa por um intenso esvaziamento, com a "dessocialização" ou "dessolidarização" da economia. Portanto, as bases deste Direito Social já não mais correspondem à nova realidade mundial.

Conforme verifica Boaventura de Souza Santos(4), neste momento se está além ou aquém da fase contratual social, ou seja, o pré-contratualismo bloqueia o acesso de quem ainda não adentrou ao modelo welferista (Estados periféricos) e, além disto, o pós-contratualismo exclui deste modelo parcela daqueles que já estavam nele incluídos. A predominância da economia financeira (especulativa) sobre a economia de produção agrava ainda mais o que o autor chama de facismo social, onde a democracia se coloca a serviço do capital.

\section{GLOBALIZAÇÃO}

De forma bastante simplificada, a aceleração contemporânea da globalização eclode pela enorme liquidez da economia internacional, a partir dos choques petrolíferos da década de 70 , e pela aplicação, na economia e finanças, dos desenvolvimentos em matérias tecno-informáticas vinculados à guerra do Vietnã.

O termo globalização surge nos anos 60 por intermédio, basicamente, das obras dos autores Marshall McLuhan ("Guerra e paz na aldeia global") e Zzbigniew Brzezinski ("A revolução tecnotrônica"). McLuhan anuncia a emer-

(4) SANTOS, B. S. Reinventar a democracia entre o pré-contratualismo e o pós-contratualismo. In: OLIVEIRA, F. de. PAOLI, Maria C. (Org.). Os sentidos da democracia. São Paulo: Ed. Vozes, 1999. 
gência da "aldeia global" recorrendo a uma extrapolação da experiência americana na guerra do Vietnã, primeiro grande conflito que, transmitido ao vivo pelas redes de TV, transforma-se, segundo ele, na primeira "realidade virtual" global para milhões de telespectadores. Por sua vez, Brzezinski dissemina as expressões "cidade global" e "sociedade global" para designar um tipo novo de reconfiguração do habitat humano pelas redes "tecnotrônicas" (conjugação de computador, TV e telecomunicações).

Posteriormente, o termo globalização, contudo, ganha ares de ideologia, confundindo-se com o processo de mundialização do capital. A globalização como ideologia (e política), tende a criar novos totalitarismo e fascismo - não o totalitarismo do Estado, ou os regimes fascistas dos anos 30 - mas um totalitarismo do mercado e um fascismo social, do pensamento único e do uso da democracia ao serviço do capital(5). Assim, a globalização traz novamente à tona a percepção da debilidade estrutural dos Estados, os quais já não têm meios de se opor aos mercados, pois a globalização tende a liquidar o mercado nacional (interno), um dos fundamentos do poder do Estado.

A globalização pelo mercado, caracterizada como um fenômeno incontornável, imposto pelo novo tipo de competitividade (flexível), apresenta-se socialmente regressiva porque coloca a sociedade a serviço exclusivo da economia, o que implica condenar o chamado Estado de bem-estar ou Estado social, e com ele a ética do social, assim como qualquer projeto de construção nacional associado à idéia de direitos sociais substantivos e de regulação democrática da economia.

Nessa perspectiva, o discurso sobre a globalização surge como o principal instrumento ideológico de legitimação das políticas neoliberais que visam à reestruturação dos processos de produção e circulação de mercadorias, marcados pela hegemonia do capital financeiro, característica esta financeirização acelerada e crescente da economia mundial - que marca uma diferença fundamental com o modo de organização prévia do capitalismo, visto que as finanças deixam de ser o complemento necessário da economia real, para converter-se em sua força condutora, subordinando os resultados e atividades desta.

(5) "Há pouco tempo, denominava-se 'regimes totalitários' os que tinham partido único, não admitiam qualquer oposição organizada e, em nome da razão de Estado, negligenciavam os direitos da pessoa; além disso, neles, o poder político dirigia soberanamente a totalidade das atividades da sociedade dominada. A esses regimes, característicos dos anos 30 , sucede, neste final de século, um outro tipo de totalitarismo, o dos 'regimes globalitários'. Apoiando-se nos dogmas da globalização e do pensamento único, não admitem qualquer outra política econômica, negligenciam os direitos sociais do cidadão em nome da razão competitiva e abandonam aos mercados financeiros à direção total das atividades da sociedade dominada (...). O Estado deixou de ser totalitário, enquanto, na era da mundialização, a economia tende cada vez vir a sê-lo." RAMONET, Ignácio. O pensamento único e os regimes globalitários. In: FIORI, José Luís et al. Globalização: o fato e o mito. Rio de Janeiro: Eduerj, 1998. 
Valendo-se da "flexibilização" das formas de contratação, de utilização e de remuneração da força de trabalho e do desmanche e/ou privatização dos mecanismos de proteção social e de regulação das relações trabalhistas, o capital amplia seu poder sobre o trabalho, reorganizando e aumentando o potencial de produção e apropriação de valor excedente.

A ideologia da globalização, portanto, faz parte de um processo mais geral de imposição do fundamentalismo neoliberal, conjunto de crenças e práticas de adaptação à nova ordem econômica mundial comandada pelo mundo financeirizado, desregulado e global. As "indústrias culturais" secundam esse esforço com uma mudança de ênfase ou de paradigmas, onde a opinião pública se confunde com a opinião publicada e a liberdade se identifica com o livre comércio.

A sociedade mundial fundada pela globalização não pressupõe um Estado mundial ou um governo mundial. Assim, ideologia da tecnologia e avanços que passam a interligar o mundo (criando a sociedade ou aldeia global) é a forma encontrada pelo capitalismo para seduzir e permitir sua sobrevivência, ao mesmo tempo em busca se eximir da culpa da miséria por ele criada, pois tal responsabilidade, a partir de então, é, literalmente (segundo discurso), uma culpa mundial.

Outro argumento utilizado pelos teóricos e defensores da globalização é que, em virtude da aproximação e, até mesmo, interligação das economias e dos seres humanos, ocorre um processo homogeneizador da condição humana e o processo conduz ao bem-estar social universal, ou seja, graças à globalização, todos são, antes ou depois, iguais e, em particular, os latino-americanos são iguais em desenvolvimento, cultura e bem-estar como os países da América do Norte e da Europa, promovendo-se, portanto, uma diminuição das desigualdades entre as nações.

Contudo, tal homogeneização não ocorre, ou, no máximo, se trata de uma homogeneização dualizadora, onde por um lado, há a homogeneização "por cima", das elites privilegiadas e, por outro, a perversa da exclusão social, da marginalização e os underclass.

Quanto à criação de bem-estar universal, ao contrário, registrou-se uma persistência, e inclusive agravamento, das disparidades socioeconômicas e educativas na maioria dos países subdesenvolvidos ou em desenvolvimento: crescimento da pobreza, cifras recordes de desemprego e subemprego e favelização das grandes cidades. Em geral, pode afirmarse que se aprofundam as diferenças de todo tipo entre os segmentos da população, tanto daquela que consegue inserir-se nos âmbitos dinâmicos da economia, como os que dela resultam excluídos.

Por outro lado, as dimensões da globalização são contraditórias entre si, tendo em vista que a ideologia (e a política) da globalização tende a ocultar - e legitimar - a lógica desigual e excludente da mundialização do 
capital e a mundialização do capital tende a impulsionar, em si, o processo civilizatório humano, isto é, desenvolvimento das forças produtivas humanas, que são limitadas - ou obstaculizadas - pelo próprio conteúdo da mundialização (visto ser ela a mundialização do capital), isto é, da mesma forma que a globalização impulsiona a desigualdade e a exclusão social, que são condição do modelo neoliberal, ela coloca possibilidades concretas para o desenvolvimento humano para além do capital, ampliando a percepção humana de mundo, bem como as possibilidades para a cooperação universal.

\section{DA QUESTÃO DO ACESSO A MEDICAMENTOS}

A partir da percepção da saúde como direito fundamental do ser humano, o acesso a medicamentos, juntamente com campanhas e políticas preventivas, passa a ser preocupação constante da população, dos agentes de saúde e governos.

Durante o período de existência do Welfare State, fundamentadas na então existente forma de ver o Direito e o papel do Estado - balanceamento das discrepâncias criadas pelo modelo liberal e proteção aos hipossuficientes - políticas sociais (e, dentre elas, de acesso a medicamentos) são implementadas, de modo a conferir efetividade ao ideal welferista. $\dot{E}$ atribuição do próprio Estado nacional levantar fundos e prover seus cidadãos com os medicamentos considerados necessários.

Com a derrocada do pensamento welferista-keyneseano e conseqüente diminuição da intervenção do Estado nas atividades privadas em virtude do predomínio do modelo neoliberal, a despeito da percepção da desigualdade social, o papel de provedor do Estado perde terreno e, como ele passa a não mais interceder no domínio econômico para implementação de programas sociais (e para levantar fundos para tais programas); sua atividade de provedor de medicamentos é, aos poucos, sendo reduzida.

A globalização, ao servir de veículo ao pensamento neoliberal, incentivou o desenvolvimento de uma economia voltada à produção, às trocas comerciais, aos resultados, abandonando a característica social anteriormente introduzida pelo Estado de bem-estar.

Assim sendo, os responsáveis pelo desenvolvimento, fabricação e comercialização dos medicamentos (conglomerados laboratoriais) voltam-se ao mercado, às estratégias de ganhos, aos esquemas de canais de distribuição, às campanhas publicitárias e à busca de proteção de suas criações, por intermédio de meios de proteção às patentes comerciais e segredos industriais.

E não somente os conglomerados comerciais e financeiros, mas também os Estados que, além de se despirem dos princípios do bem-estar, passam a ser regidos (e medidos) com base em critérios de performance, 
resultados, metas (de gastos internos, balança de pagamentos/comercial e inflação) e obediência às normas e procedimentos criados pelos organismos financeiros internacionais - Fundo Monetário Internacional, Banco Interamericano de Desenvolvimento e Banco Mundial(6).

A tecnocracia suplanta a democracia, pois questões de saúde, como o acesso a medicamentos, passam a se adaptar a orçamentos, verbas, reservas e demais normas financeiras e tributárias ${ }^{(7)}$.

Sob o manto da globalização e neoliberalismo, exacerba-se o paradoxo entre o "dever" econômico-comercial de resultados por parte dos grandes conglomerados e a percepção moral de que os produtos criados pelas farmacêuticas têm uma função eminentemente social, de combate às doenças, e moral, no sentido de melhorar a existência da humanidade. Reduzida a função social do Estado, este já não possui a antiga legitimidade para interferir nas atividades dos grandes conglomerados, buscando a diminuição de preços e aumento da oferta dos medicamentos.

Do ponto de vista jurídico, o Direito passa, novamente (como era nos tempos do liberalismo) a servir à expansão do capital, de forma que perde a função de ser o objeto, o campo privilegiado das disputas, como acontecia no seio do Welfare State, momento em que sai da simples superficialidade das disputas particulares desceu ao cerne das questões sociais, visando equilibrar a concentração de direitos potencialmente excludentes e contraditórios por meio da concessão mútua, não das partes litigantes, mas das classes representadas nas disputas, impondo mecanismos de controle e tolerância sociais mediante as restrições partidas do próprio ordenamento jurídico e não do caso específico em conflito.

No caso específico do acesso a medicamentos, o Direito não busca mais uma atuação pró-ativa, visando à consecução da distribuição social, mas simplesmente fica em estado de letargia, aguardando que os insatisfeitos se

(6) A importância da economia para os governos, acima das demais questões, inclusive acima do social, é facilmente facilmente percebida pela quase onipresença do tema econômico (notadamente se a situação é favorável) nos discursos de chefes de Estado e de governo, ao redor do mundo, inclusive no Brasil.

(7) "No mundo do ser, na realidade jurídica, o que vemos é uma confusão total dos conceitos acima expostos e uma ampla flexibilização da legalidade orçamentária. Decisões do Judiciário aos borbotões vêm concedendo gratuidade de remédios, independente de qualquer reserva orçamentária, e muitas das vezes tais remédios não guardam conexão direta com a proteção dos mínimos sociais porque não essenciais segundo a política nacional de medicamentos. (...) É de se ponderar que qualquer liminar judicial deve avaliar estas questões que envolvem a Política Nacional de Medicamentos, ou seja, verificar no aqui-e-agora se o medicamento pleiteado pelo cidadão faz parte da RENAME (Relação Nacional de Medicamentos Essenciais), ocasião em que legitimidade do pleito do cidadão acresce de valor e deve ser atendido na esfera de um justo direito social a ser protegido na forma do art. 6 da Constituição Federal. As liminares ou outras decisões que não observam estes parâmetros, ao nosso ver ademais de tudo, ferem de morte o princípio da legalidade orçamentária." NOGUEIRA, Roberto Wagner Lima. Saúde, medicamentos, desenvolvimento social e princípios orçamentários. Disponível em: <http://www1.jus.com.br/doutrina/texto.asp?id=6127>. 
levantem mediante ações individuais (ou até coletivas, mas de grupos restritos) em busca de um acesso que lhes é negado. O Direito então retorna a sua função instrumental e formal, para garantir um mínimo de segurança às atividades individuais.

No cenário mundial, desenvolve-se e consolida-se o instituto da arbitragem como alternativa aos Judiciários internos. Este fenômeno mostra claramente o retorno do Direito a sua função instrumental, uma vez que nos procedimentos arbitrais o que está em jogo é resolver rápido uma situação conflituosa econômica (nunca social, já que em regra os direitos sociais são indisponíveis), por intermédio de especialistas nos assuntos discutidos e mecanismos que permitem às partes escolher desde a lei ou norma (tratado, convenção ou mesmo equidade) pela qual os árbitros solucionarão a questão, até que ponto do problema poderá ser tratada, ou seja, os interessados poderão determinar que os árbitros não terão acesso à totalidade da operação, apenas ao ponto em discórdia, garantindo que questões sigilosas (propriedade intelectual, segredos comerciais e de indústria, ou mesmo ilegalidades) não se revelarão.

Ainda sob o aspecto internacional, surge no seio da Organização Mundial do Comércio (OMC) o Acordo sobre Direitos de Propriedade Intelectual Ligados ao Comércio (Agreement on Trade Related Aspects of Intellectual Property Rights - TRIPS). Este Acordo tem por finalidade determinar um marco legal destinado a proteger e a fazer respeitar os direitos de propriedade intelectual, coibir práticas comerciais ilegais e a estabelecer um padrão multilateral de princípios, normas e disciplinas relacionados ao comércio internacional de mercadorias falsificadas.

Dentre os tópicos do TRIPS, com relação à proteção das patentes, o acordo exige que seja concedida proteção durante 20 (vinte) anos mediante patentes a quase todas as invenções, sejam de produtos ou de procedimentos, em diversos campos da tecnologia. Além disto, se estabelecem condições detalhadas para a concessão de licenças obrigatórias ou o uso por governos de patentes sem a autorização de seus titulares.

O TRIPS leva em consideração que produtos farmacêuticos não podem ser rotulados simplesmente como mercadorias ou produtos, visto que eles ocupam um significante papel na implementação do direito à saúde, de modo que eles são classificados como produtos essenciais, enfatizando-se que tais produtos devem ser acessíveis a todos.

No Preâmbulo e nas Disposições Preliminares do TRIPS, ressalta-se que, a despeito da necessidade de promoção de adequada e efetiva proteção dos direitos de propriedade intelectual, tal proteção não poder ser considerada uma finalidade em si mesma ou uma obrigação absoluta e exclusiva, mas sim uma parte para implementar uma série de objetivos 
econômicos mais amplos. Ou seja, a proteção à propriedade intelectual deve auxiliar o desenvolvimento das políticas públicas para as quais tal proteção foi criada ${ }^{(8)}$.

Na verdade, o TRIPS não estabelece uma lei internacional uniforme, mas determina princípios e procedimentos para proteção da propriedade intelectual pelos membros da OMC. O Acordo busca determinar padrões universais de proteção à propriedade intelectual, bem como estabelece a obrigatoriedade de respeito a tais padrões. Contudo, embora alguns benefícios sociais possam advir da proteção das patentes dos medicamentos, as regras e padrões do TRIPS derivam daqueles utilizados pelos países industrializados e não necessariamente são apropriados para o nível de proteção exigido em países em desenvolvimento.

Thus, the Agreement establishes a minimum uniform regime for intellectual property rights applicable to all Members of the WTO, irrespective of the differences in their level of development (apart from the transitional periods). This fact marks a radical break with the earlier GATT strategy of differential and more favourable treatment for developing countries adopted at the Tokyo Round ${ }^{(9)}$.

Posteriormente, no $4^{\circ}$ Encontro Ministerial da OMC - conhecido como Rodada de Doha (2001), em virtude de forte pressão popular, intervenção da Organização Mundial da Saúde (OMS) e intensa repercussão da ameaça brasileira de quebra de patente de medicamentos contra a AIDS, é aprovada uma resolução sobre o TRIPS, na qual os representantes dos Estados-membros reafirmam a importância de implementar e interpretar o Acordo de modo a que este dê suporte à saúde pública, mediante a promoção de acesso aos medicamentos existentes, bem como ao desenvolvimento de novas drogas, ficando na Declaração esclarecidos e estabelecidos os mecanismos para tais ações.

A despeito das discussões sobre os resultados, reflexos e tendências do TRIPS, não podemos reduzir a questão de acesso a medicamentos apenas

(8) Neste sentido, os arts. 7 (Objetivos) e 8.1 (Princípios) do TRIPS determinam: "Article 7 Objectives: The protection and enforcement of intellectual property rights should contribute to the promotion of technological innovation and to the transfer and dissemination of technology, to the mutual advantage of producers and users of technological knowledge and in a manner conducive to social and economic welfare, and to a balance of rights and obligations. Article 8-Principles: 1 . Members may, in formulating or amending their laws and regulations, adopt measures necessary to protect public health and nutrition, and to promote the public interest in sectors of vital importance to their socio-economic and technological development, provided that such measures are consistent with the provisions of this Agreement."

(9) Who - Globalization and access to drug: implications of the wto/trips agreement, p. 40. Inicialmente, o TRIPS estabelecia um Período de Transição para que os países signatários passassem a adotar seus dispositivos de: 1 ano (1996) para os países mais desenvolvidos; 5 a 10 anos (2000-2005) para países em desenvolvimento; e 11 anos (2006) para os países subdesenvolvidos. Posteriormente na Rodada de Doha tal prazo foi estendido até 2016. 
a questões de preço, ou proteção de marcas e patentes. Na verdade, o problema faz parte de um cenário bem mais complexo, onde diversos fatores influenciam tal acesso, incluindo, dentre outros: qualidade dos diagnósticos; correta prescrição, provisão, seleção e canais de distribuição de remédios; qualidade das drogas; capacidades dos sistemas de saúde e orçamentos; existência (ou falta) de pesquisas ${ }^{(10)}$.

Vemos, portanto, que a globalização aumenta ainda mais a complexidade da questão do acesso a medicamentos, introduzindo questões como internacionalidade (tanto das relações entre Estados, como das fontes produtoras dos medicamentos), prevalência do capital sobre o social e pulverização da "culpa" (já que os "culpados", incluindo fatores socioeconômicos e ambição capitalista dos fabricantes agora se espalham pelo mundo).

Neste cenário, o Direito (principalmente os ordenamentos jurídicos internos), a despeito de reconhecer o direito ao acesso a medicamentos, vêse cada vez mais distante do centro decisório desta questão, pois o problema incorpora uma série de variáveis para as quais aquele não está preparado a equacionar e operacionalizar, em prol do benefício social.

Há que se reconhecer que se trata de um problema de imensas proporções. Segundo levantamento da OMS ${ }^{(11)}$, em 2000, mais de 55\% (cinqüenta e cinco por cento) dos países do globo enfrentavam uma situação de baixo ou mínimo acesso a medicamentos essenciais (sendo que o Brasil fazia parte dos países com mínimo acesso).

\section{CONCLUSÕES}

O acesso a medicamentos se configura em um grave problema à saúde mundial e sua solução depende de uma intrincada rede de ações, nos campos nacionais e internacionais, em todas as esferas - econômica, política, legislativa e jurídica.

(10) Neste sentido, Harvey E. Bale, representante da International Federation of Pharmaceutical Manufacturers Associations (IFPMA), em discurso proferido na reunião do Grupo ad hoc sobre Revised Drug Strategy afirmava que "Researchers from India recently published a paper entitled "Drug Utilization Patterns in the Third World" and have pointed out that there are many factors affecting access to medicines, including poor management and coordination, misuse of selfmedication, low level of public expenditure on health care, lack of basic infrastructure, inadequately trained personnel and poor allocation of financial resources (e.g., between rural and urban areas), including drugs and vaccines, and the lack of adequate health care infrastructure. There are many inexpensive generics on the market today, which raises a question: even if drugs were given away free, how far would this go to solve the access problem? Probably not very far". WORLD HEALTH ORGANIZATION. Presentations at the ad hoc working group on the Revised Drug Strategy held in Geneva on 13 October 1998. WHO (WHO/DAP/98.9). Disponível em: <www.who.int>.

(11) WORLD HEALTH ORGANIZATION. Correspondence on access to essential drugs. Geneva: Department of Essential Drugs and Medecines Policy, Febr. 2001. 
O direito ao acesso a medicamentos, assim como o direito à saúde em geral, experimentou avanços durante o Welfare State; contudo, com o advento do liberalismo e globalização, eles (como a maioria das questões sociais) perderam em parte relevância diante das imposições do mercado.

A globalização, particularmente, se encarregou de transformar o problema do acesso em questão multifacetada, espraiando a responsabilidade pelas mazelas dos países subdesenvolvidos, e em vias de desenvolvimento, para todo o mundo.

Realmente, os múltiplos fatores deste problema exigem um ataque em várias frentes, inclusive a jurídica. Porém, o Direito, cujas bases foram assentadas durante o liberalismo, sendo, portanto, faticamente voltado mais às formas do que ao conteúdo das questões jurídicas, a priori, não se apresenta aparelhado para desempenhar papel predominante na busca pelo acesso irrestrito aos medicamentos. Assim, a ciência jurídica, diante das limitações que seu próprio cerne e estrutura apresentam, em regra, não tende a ser a frente de ataque primordial ou a mais importante.

Ao que tudo indica, este papel foi reservado a grupos de pressão e sociedades organizadas, bem como à política internacional. Esta última, porém, fortemente influenciada pelo capitalismo.

Parte da responsabilidade pela falta de acesso a medicamentos pode ser creditada aos laboratórios que produzem as drogas. Porém, a despeito do crescente movimento de desenvolvimento de uma consciência de responsabilidade social empresarial, seria ingênuo esperar que entidades fundadas no comércio e que atuam sob as égides da filosofia econômicocorporativa capitalista se prontificassem a abrir mão de seus ganhos em prol do social. Caso contrário não seriam empresas, mas fundações ou organizações não-governamentais (ONGs). Não cabe, portanto, o discurso radical de que eles (laboratórios) têm a obrigação de reduzir os preços de seus produtos.

Os foros internacionais, como a OMS e a OMC, hoje se configuram como principais centros de irradiação de normas, diretrizes e pressões em prol (e contra) do acesso aos medicamentos. Obviamente, ninguém se opõe abertamente ao acesso aos remédios; entretanto, ao se defender o direito à manutenção das patentes ante um quadro dramático de falta de medicamentos, estar-se-á submetendo direitos humanos a interesses econômicos. Outros atores internacionais, como as fundações e ONG's também exercem forte influência e pressões; contudo, sua principal arma é a mobilização da opinião pública, a qual também busca ser cooptada e dominada pela ideologia da globalização.

Na prática, em relação à busca por acesso a medicamentos, o Direito ficou restrito a servir como instância a posteriori (ou última instância) para indivíduos ou grupos que lutam por uma permissão judicial para receber os 
remédios necessários. Contudo, o resultado destes pleitos é em geral limitado e restrito. Isto leva a crer que, ao menos com relação ao direito de acesso a medicamentos, a saúde voltou a ser tópica, emergencial e baseada na benemerência (fundações e ONGs).

Tal característica é verificada mesmo nos casos em que governos resolvem utilizar as válvulas de escape oferecidas pelo TRIPS para quebrar as patentes de remédios, visto que tal possibilidade somente pode ocorrer em casos de grave ameaça à saúde dos cidadãos.

Por outro lado, o Direito, após o período do Estado de bem-estar incorporou uma série de princípios e valores que, a despeito de seu formato, voltado ao procedimental, e da globalização, não foram apagados. Ela própria (globalização), apesar de servir de veículo do neoliberalismo, em se tratando de um fenômeno mundial e complexo, também promoveu uma ampliação da consciência humana para além das fronteiras dos países, permitindo o surgimento de valores e princípios realmente universais.

Tais princípios, por sua vez, servem de alicerce para questionamentos do modelo social e econômico em escala global, deixando que todos ricos e pobres - vejam mutuamente suas respectivas realidades e lutem por melhorias, notadamente para os países subdesenvolvidos e marginalizados que são os que mais sofrem com o problema de falta de acesso a remédios. Deve ser reconhecido também, o incremento de políticas, medidas e leis internas que buscam implementar o acesso a medicamentos aos respectivos cidadãos.

A inexistência de um Direito supranacional| ${ }^{(12)}$ é forte empecilho jurídico à resolução da questão do acesso, pois os maiores prejudicados são países de pouca ou nenhuma expressão internacional, exatamente aqueles aos quais a globalização reservou o ostracismo econômico-global.

$\mathrm{Na}$ busca da solução para o acesso a medicamentos, há a necessidade de re-fundar - e ampliar - a política e o "espaço público", não apenas no plano nacional ou regional, mas principalmente no plano transnacional. Tal alteração deverá resultar de uma ampla e profunda mudança da estrutura social e do atual modelo econômico, em um movimento que venha a romper com paradigmas liberais (ou neoliberais).

Sob a óptica estritamente jurídica, e levada em consideração a impossibilidade de resolução da questão do acesso mundial e irrestrito a medicamentos apenas por intermédio do Direito, a tomada de frente na luta por este

(12) O único ordenamento que pode ser considerado como supranacional encontra-se na União Européia. Todavia, a quase totalidade de seus países são desenvolvidos e se encontram na faixa de amplo acesso a medicamentos. A solução do acesso a medicamentos poderia vir da criação de um Direito supranacional que englobasse todos os Estados, notadamente os Estados Africanos e isto está longe de ocorrer. 
direito requer da ciência jurídica uma reformulação de seus alicerces, promovendo-se uma inversão na ordem valorativa dos princípios que a compõem, para que valores eminentemente sociais e humanitários ultrapassem a importância das formas e procedimentos, bem como prevaleçam sobre interesses meramente financeiros, e isto, obviamente, não será decorrência de um desenvolvimento autopoiético do Direito.

Assim, a despeito de interessante ferramenta na luta pela garantia de acesso universal a medicamentos, o Direito não parece ser o nascedouro ou a ciência onde se deve depositar as esperanças ou certezas de mudanças.

\section{REFERÊNCIAS BIBLIOGRÁFICAS}

ANTI-RETROVIRAL CONTRA AIDS. Disponível em: <http://inventabrasil net.t5.com.br/eloan.htm>.

ARRUDA JR., Edmundo Lima de; RAMOS, Alexandre Luiz (Org.). Globalização, neoliberalismo e o mundo do trabalho. Curitiba: IBEJ, 1998.

BARCELOS, Ana Paula et al. O custo dos direitos. In: TORRES, Ricardo Lobo Torres (Org.). Legitimação dos direitos Humanos. Rio de Janeiro: Renovar, 2002.

BODSTEIN, R. C. de A. Cidadania e modernidade: emergência da questão social na agenda pública. Cadernos de Saúde Pública, São Paulo, v. 13, n. 2, p. 185-193, abr. 1997.

CAMPILONGO, C. Globalização e democracia. In: $O$ direito na sociedade complexa. São Paulo: Max Limonad, 2000.

CARMO, Paulo Sérgio do. O trabalho na economia global. 2. ed. São Paulo: Moderna, 1998.

EWALD, F. A concept of social law. In: TEUBNER, G. (Ed.). Dilemmas of law in the Welfare State. Berlin: Walter de Gruyter, 1988.

FARIA, J. E. O direito na economia globalizada. São Paulo: Malheiros Ed., 1999.

MELLO, Celso D. de Albuquerque; TORRES, Ricardo Lobo (Dir.). Arquivos de direito humanos. Rio de Janeiro: Renovar, 2000. v. 2.

MOTCHANE, Jean-Loup. A OMS nos braços do mercado. Le Monde Diplomatique, Ed. Brasileira, ano 3, n. 30.

NEUMANN, F. The Change in the Function of Law in Modern Society. In: Scheuerman (Ed.). The rule of law under Siege. Berkeley: University of California Press, 1996.

NOGUEIRA, Roberto Wagner Lima. Saúde, medicamentos, desenvolvimento social e princípios orçamentários. Disponível em: <http://www1.jus.com.br/ doutrina/texto. asp?id=6127>. 
OLIVEIRA, F. A economia política da social-democracia. In: Os direitos do antivalor. Petrópolis: Vozes, 1998.

PECEQUILO, Cristina Soreanu. DE DOHA EM DIANTE - Parte I. Disponível em: <http://www.ilea.ufrgs.br/nerint/arquivoartigos/content525/content525_2/ DE\%20DOHA\%20EM\%20DIANTE.html>.

RAMONET, Ignácio. O pensamento único e os regimes globalitários. In: FIORI, José Luís et al. Globalização: o fato e o mito. Rio de Janeiro: Eduerj, 1998.

SANTOS, B. S. Reinventar a democracia entre o pré-contratualismo e o póscontratualismo. In: OLIVEIRA, F. de. PAOLI, Maria C. (Org.). Os sentidos da democracia. São Paulo: Ed. Vozes, 1999.

STIGLITZ, Joseph E. Biotecnologia: as dimensões sociais da globalização. Valor Econômico, São Paulo, 11 mar. 2004.

TAVARES, L. Globalização e o papel do Estado na proteção da vida. Conferência realizada no // Simbravisa, nov. 2004. Mimeo.

WEBER, M. Introduction. The Protestant Ethic and the Spirit of Capitalism. Trad. de Talcott Parsons. London. Routeledge, 1992 [1920].

WORLD HEALTH ORGANIZATION. Correspondence on access to essential drugs. Geneva: Department of Essential Drugs and Medecines Policy, Febr. 2001.

WORLD HEALTH ORGANIZATION. Globalization and access to drug: implications of the wto/trips agreement. Disponivel em: <www.who.int>.

WORLD HEALTH ORGANIZATION. Presentations at the ad hoc working group on the Revised Drug Strategy held in Geneva on 13 October 1998. WHO (WHO/DAP/98.9). Disponível em: <www.who.int>.

WORLD TRADE ORGANIZATION. Declaration on the TRIPS agreement and public health. Adopted on 14 Nov. 2001.

WORLD HEALTH ORGANIZATION. Annex 1C - Agreement on Trade-Related Aspects of Intellectual Property Rights.

\section{Sites:}

MEDICINS SANS FRONTIERES. Disponível em: <www.msf.org $>$. WORLD TRADE ORGANIZATION. Disponível em: <www.who.int>. 